\title{
The Incidence of Knee Stiffness Following Femur Shaft Fracture
}

\section{Musaab Mohamed Abdalla*, Mohammed Elkhatim and Elhadi Abdelrahim}

Assistant Professor, Karary University, Omdurman, Sudan

*Corresponding Author: Musaab Mohamed Abdalla, Assistant Professor, Karary

University, Omdurman, Sudan.
Received: July 02, 2021

Published: August 21, 2021

(C) All rights are reserved by Musaab

Mohamed Abdalla., et al.

\begin{abstract}
Knee stiffness is one of most common complications following femur shaft fractures, in this this study we evaluate 67 patients with femur shaft fractures for Knee stiffness.

Patients with hip fractures intraarticular distal femur fractures, pathological fractures and those who has Knee stiffness before trauma are excluded.

We found incidence of knee stiffness is $64.7 \%$, 44 patients had Knee stiffness ranging from mild to moderate and severe.

Keywords: Knee Stiffness; Femur Shaft Fractures; Trauma
\end{abstract}

\section{Background}

In our practice the knee stiffness is a common problem after fracture shaft of femur; and no study or research has been carried out about the incidence.

\section{General Objective}

The main objective is to study the incidence of knee stiffness in patient with femur shaft fracture.

\section{Patients and Methods}

Descriptive across sectional study done in Omdurman military hospital (OMH) in period from October 2014 to December 2015.

\section{Sample size}

Sixty seven patients with fracture femur were examined and well-designed questionnaire was filled out.

\section{Inclusion criteria}

All adult patients with non-pathological fractures of the femoral shaft treated in hospital operatively or non-operatively after six months from the time of trauma were selected from referred clinics.

\section{Exclusion criteria}

Patients with intra-articular knee fractures, hip fractures and patients who already have knee stiffness before the femur fracture.

Analysis of data with SPSS was done.

\section{Results}

Total number of patients studied was 67 knee stiffness is present in forty four (64.7\%) range from mild to moderate and sever.

For the sixty seven patients with fracture femur

Forty-three were road traffic accidents, twenty nine $(67.4 \%)$ of them had stiffness; fall down were nineteen, twelve $(63 \%)$ of them had knee stiffness; gun shut were four, three (75\%) of them had stiffness and open fractures were sixteen, thirteen of them had stiffness (81.2\%) and closed fracture were found in fifty one, thirty one of them had stiffness. Fractures of the ipsilateral limb 
were found thirteen, nine of them had stiffness (69.2\%); fractures of contralateral limb in five, five $(100 \%)$ of them had stiffness, patients with upper third fractures were seventeen, nine of them had stiffness (53\%); mid shaft fractures were thirty seven, twenty four of them had stiffness (64.8\%) and lower third fractures were thirteen, eleven of them had stiffness (84.6\%). 26 patients treated with Intramedullary nailing, fifteen $(57.7 \%)$ of them had developed stiffness; ten $(62.5 \%)$ out of sixteen treated with plate femur developed stiffness; nine (64.2\%) out of the fourteen treated with dynamic hip or condyle screws developed stiffness; four (80\%) out of five treated with external fixation were developed knee stiffness and six patients who treated conservatively, developed knee stiffness. out of fifty five males thirty nine $(88.6 \%)$ of them developed stiffness and five (11.4\%) out of twelve female were develop stiffness. Wound infection in relation to knee stiffness, ten (71.4\%) out of the fourteen who had wound infection developed stiffness.

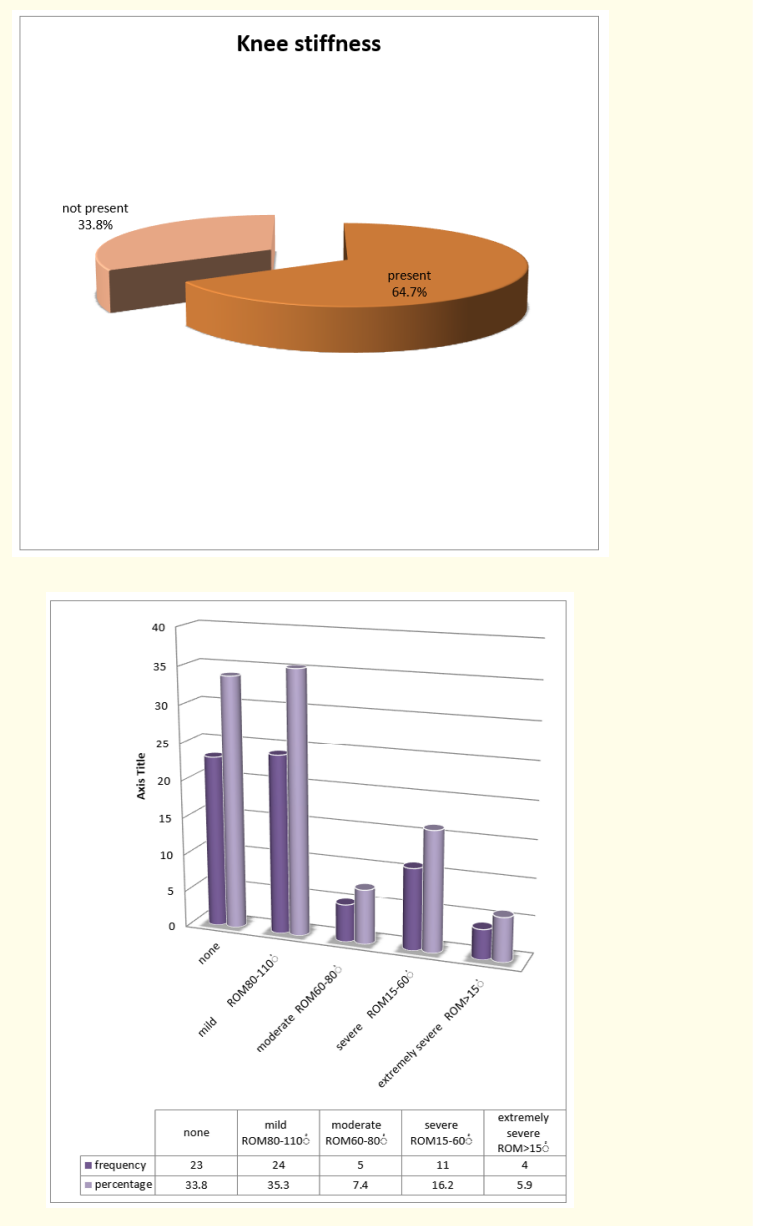

Figure

\section{Discussion}

- The percentage of knee stiffness following fracture shaft of femur is higher $(64.7 \%)$ compared to other studies [1] and we refer that to Delay in surgery an physiotherapy and early mobilization.

- Knee stiffness in this study was found in 13 out of 16 patients with open fractures (81.2\%), in comparison to $(60.8 \%)$ of closed fractures, which is the same with other studies $[1,2,5]$.

- The most frequent site of fractures is mid shaft followed by upper third and then lower third [9]. Yet the patients with fracture in lower third developed knee stiffness in (84.6\%), compared to $64.8 \%$ in mid shaft and $53 \%$ in upper third. The lower third was found to be the most frequent type which lead to knee stiffness and this the same as found by David W who said that Knee stiffness is almost inevitable in Supracondylar fracture of femur [8]. A long period of exercise is necessary but full movement is rarely regained $[4,6,9]$.

- Knee stiffness was present in $100 \%$ of patients, who had injuries in the contralateral limb. And this can be attributed to the severe limitation of both limbs mobility at the same time. But patients with associated ipsilateral limb fractures; $69.2 \%$ of them had knee stiffness. And still this account high percentage among patients with associated injuries. This the same as that found by other studies $[1,2,5]$.

\section{Conclusion}

Knee stiffness was found with high percentage in all modalities of fracture femur, in spite of being a common problem in Sudan, it has less attention in practice:

- The incidence of knee stiffness in this study is alarmingly.

- Knee stiffness is more frequent in male in a rate of eight folds to females.

- RTA was the more frequent mode of presentation of fracture femur but it came second to gun shot in causing knee stiffness.

- Knee stiffness was found with high percentage in the different modalities of treatment of fracture femur.

- Knee stiffness was present in $100 \%$ of patients, who had injuries in the contralateral limb.

- The lower third was found to be the most frequent type which lead to knee stiffness. 


\section{Bibliography}

1. Arneson TJ., et al. "Epidemiology of diaphyseal and distal femoral fractures in Rochester, Minnesota, 1965-1984". Clinical Orthopaedics and Related Research (1988): 188-194.

2. Lhowe DW. "Open fractures of the femoral shaft". Orthopedic Clinics of North America 25 (1994): 573-580.

3. Bhandari M., et al. "Operative management of lower extremity fractures in patients with head injuries". Clinical Orthopaedics and Related Research (2003): 187-198.

4. Salminen S. "Femoral shaft fractures in adults: epidemiology, fracture patterns, nonunions, and fatigue fractures. In Department of Orthopaedics and Traumatology, Department of Pediatric Surgery". University of Helsinki: Helsinki (2005).

5. Bucholz RW and Jones A. "Fractures of the shaft of the femur". Journal of Bone and Joint Surgery American 73 (1991): 15611566.

6. Ruedi T and Murphy WM. "AO Principles of Fracture Management". Thieme: Stuttgart-New York 1 (2000).

7. Miller CW., et al. "Comparison of three treatments for fractures of the diaphysis of the femur". Surgery, Gynecology and Obstetrics 146 (1978): 572-576.

8. Garland DE., et al. "Treatment of femoral shaft fractures associated with acute spinal cord injuries". Clinical Orthopaedics and Related Research (1985): 191-195.

9. Johnson KD., et al. "Comminuted femoral-shaft fractures: treatment by roller traction, cerclage wires and an intramedullary nail, or an interlocking intramedullary nail". Journal of Bone and Joint Surgery American 66 (1984): 1222-1235.

\section{Volume 4 Issue 9 September 2021}

(C) All rights are reserved by Musaab Mohamed Abdalla., et al. 